\title{
Effectiveness of Utilizing Systematic Approach to Improving Functional Writing Skills for Ninth Grade Students in Tafila Directorate of Education
}

\author{
Mohammad Alqomoul \\ Department of Curricula and Instruction, Tafila Technical University, Jordan \\ Attallah Alroud \\ Department of Curricula and Instruction, Tafila Technical University, Jordan
}

\begin{abstract}
The study aimed at investigating the effect of using systematic approach to improving functional writing skills in the public schools in Tafila Directorate of Education in Jordan. The researchers used the prescriptive approach in preparing the literal framework of the study. The subject of the study included all the Ninth graders in Tafila Directorate of Education. The sample of the study was 70 female students chosen randomly to represent the subject. The students were distributed into two groups: experimental 35 and control 35. The instruments of the study were a list of writing skills and an achievement test. The test was administered before and after the experiment. The results showed statistically significant differences in favor of the experimental group over that of control group.
\end{abstract}

Index Terms - effectiveness, systematic approach, functional writing, ninth graders

\section{INTRODUCTION}

The language is actually one major means of communication among people all over world. Human beings use it to think, write and communicate with each others. People use language for effective persistence among individuals and societies. Khater and Reslan (1988) indicated that expressional writing is one important tool of communication between writers and others far away from them. This type of writing takes various shapes such as: letters, articles, news, stories and other different pamphlets either written or audible. Using a written language, one can write memories, reports, homework and essay tests. Besides, language written form could be used in keeping records and archives, posters, advertisements, filling forms, lectures and other creative works (P. 65).

Norton (1997) focused on language written forms as something crucial for writing researches and other literary works. Language written forms are actually needed in conferences and symposiums. Some international corporations such as: "National Council of Teachers of English" published booklets explain the role of teachers in helping the students on how to write perfectly and then how to evaluate each others' writings.

The functional writing skills are so important for the students' future careers, field of works and other life aspects. They need to write administrative letters, reports and abstracts. However, the use of functional writing skills is so difficult for most of learners, either native speakers or foreign language learners, especially when they need it urgently in their daily life affairs.

Instructional approaches have been affected much as a result of the recent information explosion. So, educators have to adapt these approaches to meet the challenges and to be consistent with the modern technological revolution. New educational concepts have been emerged, these new concepts were absent in the beginning of the twentieth century. Teaching methods are also affected a lot by these recent changes, either on the speculative level or on the applicable level. That is why educators are called for making revolution on conventional methods of education to help learners recognize what is going around and to be appreciative to their own identity. Learners who are being able to select a right track which suits their own values and believes (Almanofi, 2002, 461).

Most of the time, recent instructional convention urges teachers to teach concepts and subjects separately, which leads finally to a cognitive pile of information inconsistent with itself or unpertaining with the educational nature. The only aim of this instructional convention is to support our students to pass exams with least learning. The actual instructional situation leads to graduates who think in a linear way, which is unfastened to the total framework related to the systematic approach, where we find real cognitive structure for humanitarian activities. Since we are interring the twenty first century, we need our instructional system to pass from linearity to systemic (Fahmi], and Juski, 2000, 1). Education in general and methods of teaching in particular play remarkable role in developing learners' abilities. This, in turn supports the learner to face the huge challenges and deal with them systematically. That is what we actually need for the generations to come. To achieve this goal, the teaching-learning process is required to embrace the systematic speculation. Teaching system should be totally changed at the national level to gain distinguishable learning. 
Consequently, our objectives in all fields: socially, politically, commercially and culturally will definitely be accomplished (Obeid, et al, 2005, P. 362).

A learner is considered to be one major part of the teaching-learning system, so, he must practice systematic thinking to reach comprehensive personal advancement. Teachers have to create teaching strategies based on systematic thinking. When applying these techniques inside the classroom, they urge the students to be active participants, and this, in turn; will support them to gain their learning goals. Systematic approach is actually suitable for all stages; it enhances quality of instruction in all cognitive bents and subjects. In the twenty first century, systematic approach is a must for all teachers inside the classroom. It pushes learners to be creative participants and make them willing to be competitive. That is true, because it is difficult to recognize concepts and understand relations without seeing them in their actual nature regardless other surrounding factors.

A number of studies were conducted to prove the fundamentality and effectiveness of employing systematic approach for gaining objectives of all teaching materials. Many conferences, debates and symposiums were held to emphasize the significance role of systematic approach in the teaching-learning process e g. (Education in the Global Era, Poston, USA, 2012, Current Trends in Education and its Application - Tafila Technical University - Jordan, April, 2014).

English is one important language all over the world and highly used in literal and scientific works in Jordan, especially in the later recent years, so teachers should be aware of this fact and improve their methods of teaching. The main aim of teaching a language, any language, is to encourage learners in all stages to compose reports, letters, taking down notes and making their own remarks (Al-bajeh, 1999, P. 60).

The study which conducted by (Radwan, 2008) attributed the spelling and structural mistakes of seventh graders to linear teaching system which was adopted by the teachers. In his study (Muktar, 2010) assured the necessity of using systematic approach in teaching Arabic if we need to improve its skills for the secondary stage learners.

\section{Study Problem}

The problem of the study is focused on the ninth graders' weakness in functional writing skills which may be attributed to the linear organization of the English language syllabuses. The language skills are taught separately, no attachment between the language elements, so, learners use language with no effective functions.

\section{Study Questions}

The questions of the study could be briefed to the following two forms:

- What are the functional writing skills needed for ninth graders?

- How can a systematic approach improve the functional writing skills for ninth graders?

\section{Study Hypothesis}

The study attempts to investigate these two hypotheses:

- There are statistical significant differences between the means of the experimental group on the pre and post achievement test. The significance is in favor of the post test.

- There are statistical significant differences between the grades of the two groups (experimental and control) on the post achievement test. The significance is in favor of the experimental group.

\section{Study Objectives}

The present study aimed at:

- Determining the functional writing skills needed for ninth graders.

- Constructing an achievement test to measure the students' abilities in functional writing skills.

- Investigating the effect of utilizing systematic approach in improving the functional writing skills for ninth graders.

\section{Significance of the Study}

The significance of the present study is represented in the following points:

- Calling the EFL teachers' attention to the importance of functional writing.

- Presenting lesson models adapted by systematic approach to help teachers.

- Utilizing systematic approach to teaching all English syllabuses for all stages.

\section{Limitation of the Study}

The present study is restricted to the following factors:

- The study instruments were constructed by the researchers.

- The study was conducted in the first term of the academic year: 2016-2017.

- The sample of the study was 70 female students chosen from two schools in Tafila Directorate of Education.

\section{Definition of Terms}

- Systematic approach: studying subjects and concepts within a holistic system where all relations are transparent between any subjects or any concepts which enable a learner to link what has been learnt to what will be learnt in later stages (Fahmi, and Juski 2000, p. 4). From their own experiences in the field of education, the researchers could define the systematic approach as: "Presenting the English language syllabuses through a holistic system where all relations between various concepts are so clear through definite plan represented by effectiveness and integration to achieve the objectives of functional writing". 
- Functional writing: a type of composition aimed at connecting people together to fulfill their needs, achieve their goals and organize their affairs. It could be also prescribed as a piece of writing which conveys functional objectives needed for the learner's life at school community.

\section{Study Instruments}

To achieve the objectives of the present study, the researchers used the following two instruments:

- A list of functional writing included: summarizing, report writing, letter writing, telegraph and invitation.

- An achievement test was also prepared to be applied on the sample of the study, before and after the experiment.

\section{Procedures of the Study}

To accomplish the present study, the researchers do the following:

- Revising literature and related studies in the field of functional writing skills and systematic approach.

- Preparing a list of functional writing skills suitable for ninth graders.

- Submitting the list to a group of experienced referees for judgment.

- Adapting two units form the first term material "Students' Book" to be consistent with systematic approach strategy.

- Constructing an achievement test for functional writing skills suitable for ninth grade students.

- Choosing the sample of the study and distributing it into two groups: experimental and control.

- Administering the test on the two groups before the experiment to be sure of groups' equivalence.

- Instructing the two adapted units to the experimental group according to systematic approach strategy.

- Administering the test on the two groups after the experiment.

- Collecting data and analyzing it.

- Providing some suggestion and recommendations.

\section{LITERATURE REVIEW}

* Functional writing skills:

Writing is a fundamental skill. People need it to implement their life affairs and accomplish their goals. Human beings are naturally social; no one can live alone without interacting with others. Sociologically, people need to communicate with each others, and writing is one important means of communication, especially needed when writing congratulations and condolences, reports, or a summary of an incident (Alramini, F. 2007, P.135). Functional writing has its own characteristics and its own style. These characteristics could be summed up in the following points:

- Superiority of inquiry or accountability style.

- Clarity and accuracy.

- Dealing with real-life situations.

- Direct exposition.

- Committed to certain places when writing.

- Scientific reliability.

- Concise summary.

* Writing Stages:

Writing process includes thinking and authoring which is carefully chosen by the writer. In this way, learners recognize that writing process is a repetitive work. It starts with thinking stage which precedes writing stage, then, elaboration of ideas, then, first writing, drafting and editing and finally evaluation (Arts Framework for California Public Schools, 1999, p. 26). However, before starting to write, the writer is required to think about the targeted readers, and accordingly he should write. Learners should be aware that writing is totally different from verbal communication. When speaking, spelling and grammatical errors are tolerated, but in writing such mistakes are catastrophic. Errors either, in spelling or grammar change words' meanings. So, students should learn how to find ideas, organize them, choose the correct vocabulary items and then write legibly and accurately.

Most of the language teachers confirm that writing is a renewable process. It requires rethinking and contentious evaluation (NAEP, p.1). Teachers should observe and keep in touch with the students while writing. They should guide the students to think creatively and critically before they start writing in order to express themselves clearly and persuade the readers. When writing, any writer should keep in mind the type readers he writes for, that is to say, his writing should be clear and persuasive.

Gunning (1996, p. 416) indicates that teaching writing is rapidly changed in the late years. Nowadays, teaching writing emphases on "writing stages" which is normally used by contemporary writers. Gunning adds that there is a sequence of phases which describes how writers start and finish writing professionally. He summarizes these stages by: before writing, actual writing, revision and then editing and publication.

Calkins (1986, p.13) describes a prominent pattern of writing which directs attention from final product to writing process itself and to the behavior of learners while writing. This attitude shows that final product of writing doesn't appear clearly as soon as the writer starts writing. The final product of writing could be shown after a number of repetitive trials. All writers who believe that final product of writing could be seen at the beginning of writing come to an incorrect decision (Kasim, H. M., 2000, P. 34).

A number of researchers agreed that it is difficult to isolate between the writing stages, since they are interfered; writers always transfer from one stage to another. However, the studies and researchers encompass the writing process 
are not all in agreement, some say that the phases of writing are three and some say four and some others say they are more ... etc. Regardless this controversy between researchers, (Tomkins, 1997, p. 12) summarizes the phases of writing as follows:

- Before writing: where $70 \%$ of the writing time is spent. Here, a writer prepares himself to write by choosing the subject, object of writing, organizing ideas and revising them.

- Drafting: where a writer attempts to create ideas, organize them, composing legible sentences by referring to the list in the first phase, ignoring spelling and grammatical mistakes.

- Revising: where a writer goes over the draft, reading it carefully, exchange his writing with others and rewrite it once again taking the remarks of other writers into account.

- Editing: in this phase, writers should correct spelling mistakes and write edited paper one more.

- Publishing: after correcting the mistakes and editing the corrected paper, a writer should write it again, read it aloud in the hearing of others and then, publish it in the school journal.

\section{Functional Writing Skills}

Functional writings could take some of the following forms:

- Summary making: summarizing or briefing is considered to be one remarkable field of functional writing, especially in the recent years which witness information explosion and knowledge outburst. Summarizing here means brief interpreting of main ideas, presenting them directly and to the point (Syyah, 1995, p. 230). Some define summarizing as presenting the factual text in few words concentrating on the core of the subject and putting the main ideas in it in one plain sentence (Alsaifi, p. 229). However, summarizing doesn't only mean to write the text in few words, a writer should be careful about the ideas that should be summarized. A writer, here, should work as a judge who decides which ideas should be raised and which should be ignored. He should be aware that omitting certain ideas or adding any doesn't affect the main object of the written text (Alramini, 2007, p. 292).

- Administrative letter: administrative letter is one important form of functional writing. It is actually a means of communication between two parts. These two parts could be official authority or an individual or vice versa for a functional purpose (Mahjoub, and Ali, 2004, p. 116). Administrative letter is prescribed with its objective features; it should have clear sequenced words, easiness and short sentences; far away from vagueness or hidden meaning. The sentences of the administrative letter should have no exaggeration, courtesy or any act of flattery (Alramini, 2007, p. 165). The administrative letter, in its two forms: social or official is important means of connection which facilitates discussion and communication with influential people or decision makers. Therefore, the administrative letter is significant for: saving time and effort, fast means of communication between people and states, durable document and an advertise instrument, especially for commercial advertisements.

- Reports: the report is defined as an exposition of authentic text related to a certain subject in an analytical way accompanied with evident suggestions in agreement with the final results (Alramini, 2007, 263). Bakhit, (2003, p. 187) recognizes a report as a written text for information, facts and special data related to a certain matter or subject attached with scientific analysis. The report is actually a type of functional writing in which a writer inserts a sum of information or facts about a certain person or a definite matter easily and directly which makes it clear to all readers (Mahjoub and Ali, 2006, p. 112). The reports are highly used in the governmental institutions and private sectors, since they expose clear facts and related information about a certain matter. Reports, sometimes, provide views attached to the given facts and conclusions (Mustafa, 2006, p. 196). The report as a type of functional writing is so important for all individuals and societies. It considered being a sort of scientific planning crucially needed for institutions, especially for newly appointed works, since it may help leaders and decision makers make correct substitutions (Zain, 2008, p.194). Reports promote correct decisions, especially if they are done well with accurate validity and reliability. They are used to exchange views and information between administrations and leaderships that have common interests. In this way, there will be strong relations between these institutions to draw legible plans for the future, especially with matters of common interests (Zain, 2008, p.194). However, there are certain steps that should be taken into account before starting to write a report: type of required report, objective of the report and the will to collect information and facts needed for the report. Any report should have at least the following: a title, introduction, exposure, conclusion, references and finally a signature of the writer. A report writer should be reliable, professional and have a strong vision to be able to draw a vigorous plan for the report.

- Telegram: Alramini (2007,ps.311-312) presents a telegram as a short massage sent to an individual or a group of individuals for certain occasions or urgent conditions to inform about something. Telegrams used for both grief and delighted occasions. A telegram is important form of functional writing needed by all individuals and societies, especially in social circumstances. Writing a telegram is sometimes confusing, especially when a person is ignorant of the rules of telegram writing. Writing a telegram has its own organization, and even has special sort of papers used only when writing a telegram. The most important thing in a telegram is its content which should be written briefly in one paragraph. However, when writing a telegram a number of points should be taken into account such as: clarity, briefness, organization of information, proper style for the occasion, choice of words and writing correct dress.

- Invitation: Sha'aban (2010, p. 111) perceives invitation as a piece of writing in which a writer demands form another person to come for some reason or for honorable ceremonies. Writing an invitation requires certain elements: 
invitation destiny, invitation phrase, name of targeted person, greeting, invitation details, finishing phrase, and name of sender and finally date of invitation.

\section{Systematic Approach}

Fahmi, and Juski (2000) explain that systematic approach is the process of organizing concepts and convictions through interactive systems which include all bindings between concepts and convictions. So, the concept order is the corner stone for building the structures of systematic approach.

The systematic approach is one modern trend in the field of curricula and instruction. It directs and organizes the content of syllabuses and provides the syllabuses' designers with main features before starting to plan any textbook. It also, helps the learners to be aware of the syllabus's knowledge and draw a clear profile for it before coming to its details (Obeid, 2003, p. 128). Systematic approach is actually based on the concept of regularity; which means that organizing the common learning activities in a sequence of reciprocal and interactive net. The relations within one system work together to achieve the targeted objectives, since all the contents of a curriculum and learning activities are normally based on a series of organized system (Fahmi, and Muna, 2001, p. 22). So, systematic approach always confirms the inner relations between concepts, and the role of the teacher here is to build a conceptual map where he can connect between the previous learning of students with later learning. This means that the systematic approach is the comprehensive vision of the class setting and the organization of all its components, relations and activities which lead consequently, to promote teaching-learning process.

In the pedagogical point of view, the systematic approach plays an enormous role; where a learner can compose strong relations between various concepts. Depending on the systematic approach, learners can make a kind of connection between what had been learn to what will be learn later. In the light of this system, the learner is the core of teaching-learning process (Zaitoon, 2001, p. 45). Therefore, advocators of the systematic approach insist on an educational reform where a systematic approach should be utilized to build curriculum, contents, new teaching strategies and even new evaluation process. Some of them even insist on a comprehensive change for the entire teaching-learning process (Obeid, 2003, p. 127).

\section{Significance of Systematic Approach}

The systematic approach is aiming to improve teaching-learning process till it achieves total comprehensive quality. It also aims at motivating the students to learn and making the syllabuses more attractive and more charming. Systematic approach could be employed to draw a clear profile for any subject without loosing any of its details. For this reason, the systematic approach nowadays, is a must for all systems of education to face the future challenges and troubles which impose itself on the field (Fahmi, and Muna, 2001, p. 17).

The significance of systematic approach is attributed to its comprehensive vision to meet the difficulties which stand against improving and developing the teaching-learning process. Systematic approach could be used as a base for effective discussion between teachers and students. It may encourage cooperation between teachers and learners and support teachers to be more qualified and more effective in their instruction. It could be also used as an instrument for the teaching-learning process to simplify the content and expose it functionally and meaningfully (Fahmi, and Muna, 2001, p. 63).

\section{Characteristics of Systematic Approach}

The characteristics of systematic approach in education could be summed up in the following points:

- Systematic instruction concentrates on the learner and considers him as the center of the teaching-learning process.

- Systematic instruction works hard to achieve total comprehensive quality of instruction which tackles inputs of the teaching-learning process for the sake of persuasive outputs. According to this approach the teaching process is seen as a system which includes inputs and outputs, work together to achieve targeted goals (Halpern, 1992, p. 12).

- Instructional system aims at refining and developing instructional process to achieve its objectives. So, it takes part generally, to manipulate the shortcomings of instruction.

- Systematic instruction emphasizes the construction of a teaching strategy which subjects to everlasting evaluation. This strategy aims at organizing all the procedures of instructional design in a proper way to achieve the objectives of the instructional process.

- Systematic instruction supports achieving objectives of teaching effectively, which could not be obtained by conventional methods. Some of these objectives are represented in the following: improving scientific thinking strategy, problem solving, creative thinking and sustaining other manual and mental skills.

\section{Philosophical Background of Systematic Approach}

In education, systematic approach is basically reliant on psychological theories which deal with human behavior in general and with learning process in particular. However, the researchers will present three important examples in this regard for the sake of illustration.

a. Constructive Theory: The constructive theory is ascending to the fact that knowledge acquisition is an active, constructive and continuous action done by a constant change of individual's cognitive structure. This is also done by self-adjustment of the new knowledge to be consistent with environmental knowledge pressure. The mind maintains with the knowledge basis in the short memory and recognizes it in a proper way. During the daily and continues uses of the new knowledge it transfers from the short memory to the long memory, where it remains for a long time. The constructive theory assumes that a learner can interpret any new knowledge depending on his own experiences. So, the 
meaning is built in the mind of the recipient according to his interests, needs and cognitive background. This is actually the basis of the systematic thinking; where an individual is being aware of what is going around as a clear model (Wilson, 1997, p. 47, Honebein, 1996, p.17, Jonassen, 1991, p.13-16).

b. Gagne Theory: Gagne theory was presented first as a conditional theory, since it was based on two halves, one of them concentrates on the learner as the centre of the teaching-learning process and another focuses on the conditions where learning occurs. Gagne indicated the necessity to organize knowledge hierarchy, since it is difficult for a learner to understand higher levels of knowledge before lower levels. The hierarchical formation of knowledge is designed in a way that each lower level is a base for the next level. So, he pointed out that learning settings should be always in harmony with hierarchical formation of knowledge in the field of cognition, skills, and emotional life. Gagne explained that there are eight forms of learning, moving gradually in a hierarchical related way, starting with easiest piece of learning which based on response to stimulation and ending with the most difficult piece which based on problem solving. Systematic approach is harmonious with the basis of Gagne theory, since it attempts to find a sort of contingency in the environment where learning occurs.

c. Auzubel Theory: Auzubel theory intends that human being has a sort of mental construction which enables him to perceive cognitive learning experiences. When a person passes a new experience it clings with the old one and creates a new cognitive structure. In this way, the learning occurs as a chain of construction and reconstruction with each new experience. Auzubel theory concentrates much on meaningful learning. This type of learning takes place when a new experience joins the cognitive structure of a person and becomes harmonious with what he had previously. Biologically, meaningful learning includes changes of the mental cells and its traits and psychologically, any new information or experience is automatically joined to the old ones in the cognitive structure. Meaningful learning doesn't occur if the new experience doesn't conjunct with old structure of information in the brain. Auzubel called this process "accumulated concepts". So, people are different in their learning according to the number of concepts.

When a person, who has no previous experiences, is forced to learn new ones, he actually needs to perceive them automatically and keep them in the cognitive structure. This, in turn, will urge learning other new experiences and join them to old ones. A learning process always needs connecting conjunctions to bridge new and old information together. Auzubel describes these conjunctions as concepts, which are more common and more abstracted from the new learnt information. In this way, the process of joint between old and new experiences becomes more easily, and then, the learning of a person could be described as meaningful and durable. Auzubel assured the necessity of availability of the basic concepts within a person cognitive structure in order to think properly. From Auzubl's point of view, school learning should focus on conceptual learning, especially those related to students' daily life. This could be achieved when we analyze scientific heritage to main and minor concepts. Auzubel ignored skills and attitudes, saying that they are not important to school curricula construction. As it is apparently seen in Auzubel's theory, meaningful learning should focus on the connectives between concepts, which promotes and enhances students' learning, making it more effective and more reliable.

\section{Review of Related Studies}

The researchers attempt to review some of the studies which confirm the results of the present study.

Bakhit (2003) conducted a study which emphasized the efficiency of using systematic approach in teaching in the Faculty of Sharia, especially when teaching legal sciences. He said, "The use of systematic approach contributed to high rank of graduate students" (185).

Radwan (2008) conducted a study based on the effect of systematic approach on Arabic spelling rules. He assured that using a systematic approach in teaching Arabic language skills strengthens relations between them and supports students to achieve total cognitive structure.

Probert (2009) conducted a study entitled "Improving Teaching and Learning: A systematic Approach to institutional Change". In a paper submitted to the conference on Quality of Teaching in Higher Education (QTHE). The paper outlines the key enabling factors behind the approach, both those which might be seen as institution specific and those which can be found in most universities.

Hammad (2009) executed a study to investigate the effect of using systematic approach to improving English reading and writing skills for sixth graders. The findings of the study indicated the superiority of the experimental group over control group on the post test. The superiority of the experimental group was attributed to the use of systematic approach in instruction. There were no significant differences on the post test between the means of the male and female students.

Muktar (2010) conducted a study which proved the benefitiality of using systematic approach in instruction. He studied the effect of using computer to improving the functional writing skills for secondary stage students in Saudi Arabia. The findings of his study emphasized the importance of using systematic approach in teaching functional writing skills for the first secondary students over conventional methods of instruction, which are consistent with the findings of the present study.

Alshobaki (210) carried out a study investigating the effect of systematic approach to improving concepts and visual thinking in physics for eleventh grade students in Gaza Stripe. The results showed significant differences between the means of the students on the concepts and visual thinking post test in favor of the experimental group. The significance was attributed to method of instruction. 
Mustafa (2013) conducted a study proved the efficacy of employing systematic approach in teaching historical concepts and some historic thinking skills. The sample of his study was a group of 120 students in the Faculty of Education - Asswan University. The findings of his study assured the superiority of the students who used systematic approach over those who used traditional methods.

Pardamean and Suparyanto (2014) conducted a study investigated the effect of systematic approach to improving elearning implementations in high schools. The main results of the study indicated that computer skill levels did have a direct correlation with a student's academic performance level. The database was further parsed based on demographical factors, resulting in a set of recommendations to enhance the effectiveness of e-learning.

\section{Procedures of the Study}

- Study Instruments: the instruments of the study were prepared as follows:

- The researchers made a list of functional writing skills for ninth graders.

- They constructed a test paper for these skills.

- They manipulated two units in the "Students' Book" first term, to be fit with the systematic approach strategy.

The list of the skills requires the students to do the following:

- Write legibly.

- Compose suitable headlines for the subjects they write about.

- Organize ideas logically.

- Differentiate between main and minor ideas.

- Schedule a suitable plan for writing.

- Use reporting style when writing.

- Make a summary.

- Write a report.

- Write a telegram.

- Invite people for certain occasions.

- Fill various questionnaires.

- Use figures for illustration.

- Commit to the rules of quotation.

- Correct common mistakes.

The list was given to a group of experienced referees for judgment. No remarks were given by them, so it was applied on the sample of the study. The researchers then, constructed a test for functional writing skills. The test objected to measure the effect of using systematic approach to improving writing skills for ninth graders. The test includes five domains for writing; each domain consists of three questions. A student has to select one question from each domain and answer it. The test validity and reliability were both achieved.

Test Validity: The test was judged by three experienced referees who work in the field of teaching English as a foreign language (TEFL).The referees ware asked to judge the questions in the light of their reference to the skills they measure. All the views and remarks of the referees were taken into account.

Test Reliability: The test reliability was accounted by a "Test-Retest" method. It was administered on a sample of 30 students and after two weeks the students were retested. The researchers account the test reliability using "Kuder Richardson". The reliability of the test was found to be $85 \%$ which is suitable for the present study.

Two units were chosen from the "Students' Book" for ninth graders and manipulated to be fit with the techniques of systematic approach.

Study Sample: The sample of the study was chosen randomly to represent the subject of the study. 70 female students were chosen from two cooperative schools, (Fatima Bint Elyaman and Bilat Alshuhda), one section from each school. The students were distributed into two groups "experimental and control". The test was applies first on the two groups "experiment and control" to measure equality between them. The two adapted units were taught to the experimental group for three weeks. Then, the sample of study was retested. Data was collected and analyzed.

\section{DiscuSSION OF FINDINGS}

To test the credibility of the first hypothesis which says "There are statistical significant differences between grades of the experimental group on the pre-post test. The significance is in favor of the post test as shown in table (1) below.

TABLE (1)

MEANS AND STANDARD DEVIATION OF EXPERIMENTAL GROUP ON PRE-POST TEST

\begin{tabular}{|c|c|c|c|c|}
\hline Group & Test & Means & SD & T-test \\
\hline \multirow[t]{2}{*}{ Experimental } & Pre-test & 5.28 & 2.36 & \\
\hline & Post-test & 7.86 & 2.75 & 4.77 \\
\hline
\end{tabular}

As it is clearly shown in table (1) above that there are statistically significant differences between the means of the grades of the students in the experimental group in favor of the post test. 
To test the cridability of the second hypothesis which says "There are statistically significant differences between the means of the grades of the students on the post test". The significance is in favor of the experimental group. Table (2) below illustrates the differences.

TABLE (2)

MEANS AND STANDARD DEVIATION OF THE STUDENTS' GRADES ON THE POST TEST

\begin{tabular}{|c|c|c|c|c|}
\hline Group & Test & Means & SD & T-test \\
\hline Experimental & Post-test & 7.67 & 2.53 & \\
\hline Control & Post-test & 5.07 & 2.34 & 4.91 \\
\hline
\end{tabular}

As it is clearly shown in table (2) above that T-value is higher than significance level $(\alpha=0.05)$ which indicates statistically significant differences between the means of the two groups on the post test. The significance is in favor of the experimental group. This result proves the cridability of the second hypothesis.

The findings of the present study support the fact that using systematic approach in instruction is much better than using linear methods of instruction. Applying systematic approach in instruction enhances learning and urges students to be active, creative and cooperative participants. It also, enriches the syllabuses' activities and makes them more attractive and more incentive to the students.

The findings of the present study are highly consistent with the findings of (Radwan, 2008) who assured that using systematic approach in teaching Arabic language skills strengthens relations between concepts and supports students to achieve total cognitive structure. Hammad (2009) indicated the superiority of the experimental group over control group on the post test. The superiority of the experimental group was attributed to the use of systematic approach in instruction. Muktar (2010) emphasized the importance of using systematic approach in teaching functional writing skills for the first secondary students over conventional methods of instruction. Alshobaki (2010) showed significant differences between the means of the students on the concepts and visual thinking post test in favor of the experimental group. The significance was attributed to method of instruction. Mustafa (2013) indicated the superiority of the students who were taught by systematic approach over those who used traditional methods. Pardamean, and Suparyanto (2014) investigated the effect of systematic approach to improving e-learning implementations in high schools. The main results of their study indicated that computer skill levels did have a direct correlation with a student's academic performance level.

\section{SugGeSTiOnS AND RECOMMENDATIONS}

In the light of the findings of the present study, the searchers suggest and recommend the following:

- Paying more attentions to functional writing skills.

- Training EFL teachers to teach functional writing skills.

- EFL supervisors should focus on writing skills in general and functional writing skills in particular.

- Balancing between teaching the four language skills.

- Studying the effect of improving listening and speaking skills on reading and writing skills.

- Using systematic approach to improving all the four language skills.

- Constructing a genuine systematic approach program for the basic stage students to improve writing skill.

\section{REFERENCES}

[1] Albajeh, A. (1999). Foundations of Arabic Language Instruction - Theory and Practice, Dar Elfikr, Amman, Jordan.

[2] Alkuaibiski,Z. K. (2008). Language Skills, Dar Almaarifeh Aljamiyyeh, Cairo, Egypt.

[3] Almanofi, S. J. (2002). Effectiveness of Systematic Approach in Teaching Mathematics and its Effect on Systematic Thinking of Secondary Stage Students, A paper presented in the Forth Conference for Curricula and Instruction, Ainshams University, Cairo, Egypt.

[4] Alramini, F. (2007). Adequate Reference in Composition and Professional Creativity, Dar Alkitab Aljamee, Alain, UAE.

[5] Alshobaki, F. M. (2010). Impact of Employing Systematic Approach to Improving Concepts and Visual Thinking in Physics for Eleventh Grade Students, Unpublished MA. Thesis, Islamic University, Gaza, Palestine.

[6] Alsaifi, I. (2008). Art of Summary, Dar Almaarifeh Aljamiyyeh, Beirut, Lebanon.

[7] Arts Framework for California Public Schools. (1999). Adopted by California State Board of Education, (1998). National Assessment of Educational Progress (NAEP), USA.

[8] Bakhit, M. A. (2003). Systematic Approach in Teaching Legal Sciences, $3^{\text {rd }}$. Arab Conference: "Systematic Approach in Instruction and Learning", Faculty of Sharia, Jerash University, Jordan.

[9] Calkins, L. M. (1986). Art of Teaching Writing, Portsmouth, NH: Heinemann.

[10] Current Trends in Education. (2014). Tafila Technical University, Tafila, Jordan.

[11] Education in the Global Era. (2012). Bridgewater State University, Poston, USA.

[12] Fahmi, A. F. and Juski, J. (2000). Systematic Curriculum in the Face of Future, Recent Educational Challenges, Dar Alma'arif, Cairo, Egypt.

[13] Fahmi, A. F. and Muna. A. (2001). Systematic Curriculum Facing Recent and Future Challenges, Dar Alma'arif, Cairo, Egypt.

[14] Gunning, T. G. (1996). Creating Reading Instruction for All Children, Toronto: Allyn and Bacon.

[15] Halpern, D. F. (1992). Thinking Skills in Science and Mathematics, New Jersey, Lawrence Elburn Association. 
[16] Hammad, K. M. (2009). Developing English Reading and Writing Skills for Sixth Graders in Palestine by Using Systematic Approach, Unpublished Ph. D. Thesis, Ainshams University, Cairo, Egypt.

[17] Honebein, P. C. (1996). Seven Goals for the Design of Constructivist Learning Environment, Publication Englewood, New Jersey.

[18] Jonassen, D. H. (1991). Evaluating Constructivist Learning, Educational Technology, 28(11), 13-16.

[19] Kasim, H. M. (2000). Effectiveness of Employing Modern Approaches to Improving Writing Composition for Basic Stage Students, Unpublished Ph. Thesis, Faculty of Education, Ainshams University, Cairo, Egypt.

[20] Khattar, A. and Reslan, M. (1988). Effectiveness of Systematic Approach to Improving Writing Skill, Dar Alshawaf, Cairo, Egypt.

[21] Mahjoub, A. and Ali, M. A. (2006). Language Skills, $4^{\text {th }}$. Edition, Publications of Sudan Open University.

[22] Muktar, A. (2010). Impact of Using Computer to Improving Functional Writing Skills for Secondary Stage Students in Saudi Arabia, Journal of Reading and Knowledge, Ainshams University, Cairo, Egypt.

[23] Mustafa, M. M. (2013). Effective ness of Systematic Approach to Improving Some of Historical Concepts and Historic Thinking for $2^{\text {nd }}$. Preparatory Students, Unpublished MA Thesis, Faculty of Education, Asswan University, Egypt.

[24] Norton, Dona, A. (1997). Effective Teaching of Language Arts, Merrill, an Imprint of Prince Hall.

[25] Obeid, W. et al (2005). Recent Trends for Curriculum Construction, a paper presented in the Arab $3^{\text {rd }}$. Conference for Systematic Approach in Learning and Instruction, Ainshams University, Cairo, Egypt.

[26] Pardamean, P. and Suparyanto, T. (2014). Systematic Approach to Improving E-learning Implementation in High schools, Turkish Online Journal of Education Technology, 13(3), 19-26.

[27] Probert, B. (2009). Improving Teaching and Learning: A systemic Approach to Institutional Change, A paper submitted to the "What Works Conference' on Quality of Teaching in Higher Education (OECD) Program on Institutional Management in Higher Education (IMHE), Istanbul Technical University (ITU), Istanbul, Turkey.

[28] Radwan, R. A. (2008). Effectiveness of Systematic Approach in Teaching Spelling Rules for Preparatory Stage, Unpublished Master Degree, Faculty of Education, Alminya University, Egypt.

[29] Sha'aban, M. (2010). Functional and Creative Writing, Dar Almaseera for Publication and Distribution, Amman, Jordan.

[30] Syyah, A. (1995). Studies in Standard Arabic and its Methods of Teaching, $1^{\text {st }}$. edition, Dar Alfikr Allubnani for Printing and Publication, Beirut, Lebanon.

[31] Tompkins, G. E. (1997). Literacy for the $21^{\text {st }}$. Century: A balanced approach, New Jersey: Merrill Prentice Hall.

[32] Wilson, C. (1997). A review of Cognitive Teaching Models, Educational Technology for Research and Development, 39 (4), 47-64.

[33] Zaitoon, H. (2001). Instructional Design - Systematic View, $1^{\text {st }}$. edition, Alam Alkutob for Publication and Distribution, Cairo, Egypt.

Mohammad Alqomoul was born in Tafila-Jordan in 1957. He received his PH D. degree in TEFL from Amman Arab University for Graduate Studies in 2005.

$\mathrm{He}$ is currently an associate professor in the Department of curricula and instruction - Tafila Technical University-Jordan. His research interests include language and curricula.

Dr. Mohammad is now a head of the scientific committee at the Faculty of Educational Sciences in TTU.

Attallah Alroud was born in Tafila-Jordan in 1950. He received his PH D. degree in TEFL from Bagdad University in 2005.

$\mathrm{He}$ is currently a full professor in the Department of curricula and instruction - Tafila Technical University-Jordan. His research interests include language and curricula. 